\title{
HISTORIOGRAFÍA Y POLÍTICA EN LOS HISTORIADORES DE INDIAS DE LA PRIMERA MITAD DEL SIGLO XVIII
}

Cuando nos acercamos al estudio de esta realidad compleja y contradictoria que es el siglo XviII español, la perspectiva en que percibimos las relaciones entre microestructuras económicas, políticas, institucionales, sociales y culturales del país tiende imperceptiblemente hacia una especie de "presbiopía", defecto que provoca incapacidad de distinguir los objetos con la nitidez necesaria. Una España zigzagueante en la búsqueda de una identidad a la altura del clima de reorganización político-económica, y de redefinición de los contenidos y del papel de la cultura - clima que trastorna luminosamente a toda Europa-, aparece, como resultado de esta "presbiopía", vista a vuelo de pájaro. En el vuelo rasante sobre los hechos particulares esta visión, que tendría que ser una hipótesis conducida a su verificación experimental mediante una minuciosa investigación, más bien difumina los hechos de modo que las distintas figuras de los protagonistas y la diacronía de sus obras se resisten a ser abarcadas por un concepto general en el que deberían estar forzosamente comprendidas.

Y sucede así porque los análisis, a veces muy sutiles y penetrantes, del pensamiento de un autor o bien recorren el itinerario genealógico de sus ideas o bien hacen reconocibles su interna articulación, y olvidan simplemente interrogarse sobre el significado que tiene la fecha de publicación de sus obras. Fecha, y esto lo tendríamos que tener siempre presente, que no está sólo determinada por la voluntad del autor, sino especialmente por la voluntad de la censura inquisitorial. En la nueva situación política conseguida con el éxito de la Guerra de Sucesión, la

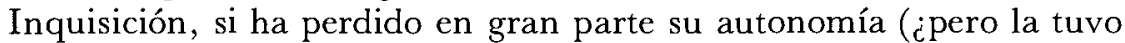
verdaderamente alguna vez? $)^{1}$, sigue manteniendo su poder sólo porque es el "brazo eclesial" de las elecciones "seculares" del poder. La publicación de una obra tiene consiguientemente una fuerte valencia política, y se recibe como una manifestación del proyecto cultural del equipo de ministros que controla y guía en aquel momento la política del Estado.

1 Cf. Bernardino Llorca, La Inquisición en España, Barcelona, 1936, pp. 309-310. 
No hay que olvidar nunca la dificultad y tortuosidad del recorrido que hombres políticos como Macanaz, Riperdá, Patiño, Campillo, Carvajal y Ensenada (para limitarnos a los ministros "preilustrados" de los dos primeros reinados de Felipe V y Fernando VI) tuvieron que emprender para que, por un lado, España saliese del estancamiento en que se encontraba, abriendo el paso a las reformas, y, por el otro, para que en este plan se insertasen los intelectuales deseosos de abrirse a las nuevas ideas como instrumentos necesarios para involucrar en este proyecto a la "sociedad civil". Y es por esta razón que la descodificación de los textos (no sólo de contenido económico o político, sino también simplemente "novelesco") necesitaría la utilización de una hermenéutica más flexible y abierta para captar la compleja polisemia histórica de la producción cultural.

Si estas atenciones metodológicas se aplican escasas veces en el análisis de la producción literaria del siglo XVIII, cuando tropezamos con la enorme e inexplorada producción historiográfica de esa época, el carácter muy a menudo erudito de la misma parece como legitimar una historia de la historiografía que sigue aún los anticuados esquemas de lectura de un Fueter, un Meinecke, un Croce, para citar sólo tres nombres significativos.

No viene aquí al caso reabrir la vieja y ya rancia polémica sobre el XVIII "antihistoricista", contrapuesto al XIX, "siglo de la historia". "Nunca la historia estuvo tan de moda como hacia la mitad del siglo XVIII - escribe Ferguson en su clásica obra sobre el Renacimiento en el pensamiento histórico-, y raramente la historia estuvo tan bien escrita y en tan perfecta consonancia con las orientaciones culturales del tiempo"2. Denis Hay afirma justamente que es en el siglo XVIII cuando se registra "la convergencia del historiador tout court y del historiador 'anticuario', y el desarrollo de un tipo de historia más complejo que la simple narración de acontecimientos relativamente recientes, o sea la historia entendida como una actividad que requiere investigación y análisis"' 3 . Sólo que a estas afirmaciones no han seguido unas investigaciones en profundidad de la inmensa producción historiográfica dieciochesca. Y en el caso de la historiografía española del XVIII, salvo rarísimas excepciones, queda campo abierto por arar.

Como ha subrayado con su acostumbrado acierto Maravall, también en España la historia "en cierta medida, se convierte en un instrumento crítico, en una vía de reforma intelectual, y, llegado el caso, en un apoyo para las pretensiones de reforma social" ". En efecto, si lo que motivaba a los historiadores a emprender el camino de la ordenación

2 Wallace K. Ferguson, The Renaissance in historical thought, Cambridge, 1948. Cito por la trad. ital., Bologna, 1969, p. 118.

3 Denis Hay, Annalists and historians. Western historiography from the eighth to eighteenth centuries, London, 1977. Cito por la trad. ital., Bari, 1981, p. 179.

4 J.A. Maravall, "Mentalidad burguesa e idea de la historia en el siglo XviII", ROcc, 36 (1972), p. 253. 
del tiempo histórico (cuando obviamente esta ordenación no se limitaba a ser una simple recopilación de documentos o construcción de crónicas estructuradas según el criterio medieval de los anales) era la voluntad de encontrar una significación general de los acontecimientos, verlos como "interdependientes", y por lo tanto identificar en ellos una "unidad de sentido", como diría Koselleck ${ }^{5}$. Esta unidad de sentido no podía dejar de concretarse en un juicio de valor y, consiguientemente, en un "mensaje" político. Y los grupos que detentaban o aspiraban a tener el poder, sea para dirigirlo en el camino de las reformas o bien en el camino contrario, "necesitaban, de una parte, que la Historia les diera cuenta de la situación y les enseñara o bien los resortes de que podían servirse o inversamente aquellos cuya acción tenían que anular; de otra parte, ella podía fortalecer su posición, poniendo en claro las razones de su prestigio y de su influencia, en el nuevo régimen de estratificación que debería servirles de apoyo"'6.

Me limitaré aquí a dar algunas indicaciones de cómo es posible un análisis de la producción historiográfica española de la primera mitad del siglo XVIII, intentando superar un modelo de historia de la historiografía, estructurado como una serie de monografías sobre distintos historiadores o como una secuencia de problemas historiográficos, que se desarrollan en un espacio enrarecido, en el que un historiador recoge el hilo de otro historiador o deshace la madeja precedente y propone recorridos interpretativos distintos o diversos sistemas de descodificación de la realidad histórica. Un análisis de la producción historiográfica que se aleje también, sin desconocer desde luego su validez, de la contaminación de las ciencias históricas y la semiología. Es decir, una historia de la historiografía como historia de los principios teóricos que determinan la escritura historiográfica en las distintas épocas o, en el límite, como análisis del discours de l'histoire ${ }^{7}$. Y en esta producción historiográfica operaré una ulterior delimitación: tomaré en consideración sólo el grupo de los llamados "historiadores de Indias" durante ios reinados de Felipe V y Fernando VI.

Esta elección de un aspecto particular de la producción historiográfica de la primera mitad del siglo XviII está determinada por el hecho contingente de habérseme amablemente solicitado algunas observacio-

5 Cf. R. Koselbeck, "La storia sociale moderna e i tempi storici", en La teoria della storiografia oggi, ed. P. Rossi, Milano, 1983, pp. 141-158. Este nuevo concepto de historiografía, subrayado por Koselleck, lo podemos encontrar en definiciones muy penetrantes, como la de Burriel de "serie encadenada", contrapuesto al viejo concepto de "hechos desnudos". Cf. Cartas eruditas y críticas del P. Andrés Marcos Burriel de la estinguida Compañia de Jesús. Dalas a la luz don Antonio Valladares de Sotomayor, s.l., s.f., p. 232 (escrita en 1751), y también en la definición de JuAn Pablo Forner, de "sistema de unidad que debe encaminar todas las lineas al centro común", cf. Discurso sobre el modo de escribir y mejorar la historia de España, en Obras, Madrid, 1843, p. 89.

$6 \mathrm{~J}$. A. Maravall, art. cit., p. 256.

7 Cf. las observaciones sobre este tema de R. BARTHES, "Le discours de l'histoire', Poétique, 1982, núm. 49, 13-21. 
nes sobre un "tema americano"'. Pero, como siempre acaece para quien la "dinámica de la curiosidad" es la motivación profunda de su oficio, la contingencia ha sido, espero, el afortunado pretexto para abrir y leer, en una perspectiva distinta, una página más de las tantas que quedan por abrir o que se han abierto mal, del gran libro de la Ilustración española y de los años de su gestación.

Quisiera añadir otra observación preliminar. La historiografía indiana, y no me refiero sólo a la del XVIII, bastante escasa como veremos, sino a la que incluye los grandes nombres de la tardía historiografía renacentista y barroca, con la que los historiadores dieciochescos no interponen una verdadera solución de continuidad ${ }^{8}$, tiene, por el objeto mismo de su narración, una característica particular. Es decir, que los "historiadores de Indias", recuperando para el interés historiográfico no sólo el conjunto de los acontecimientos de la conquista o la problemática de su "justificación", sino la realidad compleja y fascinante - "otra" en relación a la nuestra- de las costumbres de los indios, del carácter entrópico de su "cultura", o, si queremos emplear el término volteriano, la histaire des mours del Nuevo Mundo, anticipan el modelo de la gran historiografía ilustrada, que Kant resumirá en la famosa frase: "hasta ahora la historia se ha modelado sobre la cronología, ahora se trata de que la cronología se modele sobre la historia"" .

Además en la historiografía sobre las Indias hay que subrayar la presencia de un hecho, que no me parece que haya sido puesto de relieve suficientemente. La historiografía relativa a la realidad peninsular es una versión gubernativa, "sin la otra cara de la historia, sin tentaciones de contrahistoria", que refiere lo que el poder "piensa que haya acaecido, y puesto que no expone todo lo que sabe, refiere lo que considera oportuno que se sepa" 10 . Ahora bien, la historiografía indiana no se escapa de la antedicha estructura de versión gubernativa; por el contrario, es una de las armas ideológicas más importantes para justificar nada menos que el hecho macrohistórico de la conquista. Sólo que la articulación tan intrincada de esta justificación y la realidad con que

8 La carencia de una verdadera solución de continuidad entre la historiografía dieciochesca y las tardías renacentista y barroca, es un tema que necesitaría de ulteriores reflexiones. Ya sea en dirección de la permanencia de un background renacentista, en la línea, sólo por mencionar un nombre, de un Pomponio Leto, es decir, del método filológico de la verificación de las fuentes (en efecto, no hace falta recurrir, como se hace, al más reciente ejemplo de la filología histórica de los maurinos o al pirronismo bayliano). O, también, en la utilización de la realidad "otra" de las Indias, como serie de exempla filosóficos, en una línea que desde la contaminación renacentista y barroca, de nueva realidad e historia antigua, llega hasta la utilización de la misma contaminación de un Diderot o de un Raynal.

9 Inmanuel Kant, Antropologie (1798), en Werke, ed. W. Eischedel, Darmstadt, 1964, t. 6, p. 503.

10 Tomo prestadas las palabras, relativas a la historiografía veneciana, de Gino Benzoni, Introduzione a storici e politici veneti del Cinque e Seicento, eds. G. Benzoni y T. Zanato, Milano-Napoli, 1982, p. xxix. 
tiene que enfrentarse, produce no sólo la bien conocida línea interpretativa que, por no ampliar demasiado el discurso, podemos llamar "lascasiana", sino la emergencia, ora espontánea, ora abiertamente polémica de una idea fundamental: la historia de los progresos de la "civilización" puede coincidir con la historia de los regresos de la sociedad.

Pero volvamos a nuestro tema específico. Las postrimerías del reinado de Carlos II - ya no tan teñidas por la historiografía de colores excesivamente oscuros, por mucho tiempo casi cristalizados, pero que continúan viéndose como momentos de decadencia y de transición crítica - registran una fuerte disminución en la producción historiográfica sobre las Indias. Ya no se aceptaban las motivaciones originales de justificación de la conquista, y las relaciones entre la realidad americana y la peninsular se estaban articulando de una manera muy distinta. La prioridad que la política española había dado al sector europeo permitía que se estructurara una realidad poliforme en las Indias, y se formase en ellas una conciencia política que mirara hacia dentro más que medirse, cargándose de complejos, con la realidad de la Península.

América, además, no causaba ya muchos problemas a la Corona. Es bien sabido que ni la defensa de las Indias contra la piratería inglesa y holandesa implicó tan enormes sacrificios como se pretendía, ni la producción de la plata registró bajas tan catastróficas como se ha dicho. Es más, el volumen del comercio se incrementó, aunque desapareció el monopolio castellano del tráfico atlántico.

La política tributaria de la Real Hacienda pesó sobre las Indias más que por los nuevos impuestos del papel sellado y de la unión de armas, por el aumento del fenómeno de la venta de cargos, por los indultos de delitos y por la composición de tierras. Esta política produjo por un lado la formación de una aristocracia local directamente ligada a la Corona y, por el otro, el fenómeno de decisiva importancia del decaimiento de la encomienda y su sustitución por la hacienda. Este hecho significó el progresivo cambio de una economía basada en la explotación minera a otra basada en un tipo de agricultura especializada (cereales, azúcar, algodón, seda, índigo), y la transformación de muchas tierras en latifundios de pastos, con el consiguiente despegue de unas florecientes industrias pecuarias ${ }^{11}$.

En este contexto la historiografía oficial sobre las Indias de los últimos años del reinado de Carlos II marca el paso. Al decaer tanto la tensión intelectual que corría bajo el descubrimiento "mítico" de las "cosas de encantamiento" del Nuevo Mundo, según las llamaba Díaz del Castillo, como la tensión polémica de la "leyenda negra”, el cargo de cronista mayor, que a razón justamente del enfrentamiento Las

11 Resulta inútil hacer una bibliografía de todas estas problemáticas, fáciles de encontrar en Luis Navarro García, Hispanoamérica en el siglo xviii, Universidad de Sevilla, 1975. Cf: también la reciente y excelente síntesis de Guillermo Céspedes deL Castillo, América hispánica (1492-1898), en Historia de España, dirigida por Manuel Tuñón de Lara, Barcelona, 1983, t. 6. 
Casas-Sepúlveda había sido creado por Felipe II, estaba resgistrando un considerable calo de nivel. La crisis política de final de siglo, en lo que se refiere a los asuntos americanos, registra también la tónica general de incompetencia y mediocridad. Así es que todo el material que Pedro Fernández del Pulgar, nombrado cronista mayor en 1686, había recopilado con gran cuidado - aunque de manera muy confusa y con criterios anticuados - fue parcialmente recogido en cuatro gruesos tomos en folios con el título de Historia general de las Indias occidentales, organizando los acontecimientos según el primer modelo de las Décadas de Antonio Herrera y Tordesillas. A pesar de haber obtenido censura favorable y licencia de impresión ${ }^{12}$, esta obra quedó sepultada en los archivos y allí permanece todavía.

La labor de Fernández del Pulgar, aunque muy atenta y escrupulosa, era evidentemente inutilizable por las ineptas fuerzas políticas que intrigaban en la Corte, y por dos razones fundamentales. La primera es que el problema de las relaciones de la Corona con las Indias de hecho había pasado a manos de los nuevos hombres de empresa catalanes y vasconavarros, en el contexto general del comienzo de aquel proceso de progresivo desplazamiento de los núcleos de decisión económica desde el centro a la periferia, que se consolidará en el período siguiente. Si a una inexistente política indiana central de nada le servían las noticias recogidas por su cronista mayor, menos todavía podían ser útiles a unos hombres de negocios, que tenían otras fuentes directas a las que podrían recurrir para sus problemas concretos. La segunda razón consiste en que la finalidad ideológica de la obra de Fernández del Pulgar, de vindicar "a los principales conquistadores de las injurias que les imputan los extraños y domésticos" o "los hechos de los españoles de las calumnias de los extrangeros y propios", como dicen los subtítulos de los Tropheos gloriosos de los Reyes Cathólicos de España y de la Historia verdadera de la conquista de la Nueva España por don Fernando Cortés ${ }^{13}$, si por un lado era una tentativa de dar una respuesta a la utilización de las argumentaciones filo-lascasianas, aún vigente en las publicaciones europeas y que se radicalizaría pronto todavía más a partir del problema de la sucesión ${ }^{14}$; por el otro lado era una respuesta, que por su misma estructura de farragosa erudición resultaba absolutamente inutilizable. Esto no le resta nada, sin embargo, al valor e interés de la producción historiográfica de Fernández del Pulgar, que tendría que ser estudiada colocándola en el contexto, al que a justo título pertenece, de aquel criticis-

12 Cf. Rómulo D. CARBia, La crónica oficial de las Indias occidentales, La Plata, 1934, pp. 213-220

13 Sólo de los Tropheos existe una edición moderna (Madrid, 1951). Para las otras obras de Fernández del Pulgar, véase B.N.M., mss. 2595-96, 2796-99, 2997-98 y 3002.

14 Cf. las ediciones de la Brevisima relación de LAS CASAS (Amsterdam, 1692 y 1698; London, 1699; Newe Welt, 1697; Berlin, 1690; Paris 1697 y 1701). 
mo historiográfico en el que se estaban moviendo hombres como Sáenz de Aguirre, Manuel Martí y Nicolás Antonio.

Éste es el contexto en que hay que situar también la labor erudita de colección y cotejo de documentos, así como la exploración de archivos de Luis Salazar y Castro, nombrado cronista mayor en 1698, que ciertamente tuvo la desgracia de encontrarse envuelto en las convulsiones políticas provocadas por la Guerra de Sucesión, pero que aun permaneciendo en el cargo hasta 1734, no consiguió tampoco publicar nada. Sus papeles, que se conservan hoy en el Archivo de la Academia de la Historia, no tuvieron por lo tanto circulación e incidencia alguna en los nuevos problemas que se pusieron en movimiento después del cambio de dinastía.

Si los cronistas mayores obtuvieron poco éxito y despertaron poco interés, no mucho más lograron los otros. Casi inadvertida, por ejemplo, pasó la publicación en Amberes en 1688 de la primera parte de la Historia general de las conquistas del Nuevo Reino de Granada, del canónigo y después obispo de Cartagena de Indias, Lucas Fernández de Piedrahita, que compuso su historia con el simple intento de reducir a un "lenguaje menos antiguo", como escribe en el prólogo, las clásicas crónicas, que había podido leer durante su estancia en España en 1662, cuando fue llamado por el Consejo de Indias a responder a unos cargos que se le habían hecho' ${ }^{15}$. Empresa personal y aislada la suya, que como tal se quedó, a pesar de los elogios que de ella hace Feijoo ${ }^{16}$, tanto que sorprende un poco la publicación del primer tomo, y no se comprende cómo en seguida fue interrumpida la publicación del segundo.

No se consiguió, en cambio, publicar una obra llena de encanto y de una documentación preciosa sobre paisajes y costumbres de Guatemala, la Recordación florida. Discurso historial, natural, material, militar y político del reino de Goathemala, del regidor y alcalde mayor de aquellas tierras, don Francisco Antonio de Fuentes y Guzmán. Redactado probablemente en la última década del siglo, el manuscrito se envió al Consejo de Indias para su publicación, la que no se efectuó hasta 1822. Es probable, pero se trata sólo de una hipótesis, que el abogado y relator de la chancillería de Valladolid y relator del Consejo de Indias, don Juan Villagutierre de Sotomayor, pusiese obstáculos a la publicación de la Recordación florida, para dar paso a la publicación en Madrid, en 1702, de su Historia de la provincia de Itzá, reducción y progressos de la del Lacandón $y$ otras naciones de indios bárbaros, de las mediaciones del reyno de Guatimala a las provincias de Yucatán en la América septentrional. Caso éste muy típico

15 Cf. Francisco Esteve Barba, Historiografía indiana, Madrid, 1964, pp. 316-317.

16 Feijoo tiene en mucha consideración la Historia de Piedrahita, que nombra, junto a otros grandes historiadores, a Garcilaso el Inca, José de Oviedo, Alonso de Ovalle, etc., quizás para estimular al cronista mayor a dar una voz "oficial" a su nueva visión del problema de la historiografía indiana. Cf. G. STIFFoni, "II tema americano come momento della politica culturale del Teatro crítico di Feijoo", Studi di letteratura ispanoamericana, 1983, núms. 15/16, p. 97. 
del enfrentamiento entre castellanos y criollos, y expresión de la voluntad política de marginación de los "españoles americanos", de cuya temática se ocupará Feijoo en los tomos II y IV de su Teatro crítico ${ }^{17}$. Sin embargo, no obtuvo privilegio de impresión su Historia de la conquista, pérdida y restauración del reyno de la Nueva México en la América septentrional, a pesar de ser obra interesante y documentadísima. El seglar Villagutierre había tropezado en esto con el "monopolio" de la historia de la conquista y evangelización de la Nueva España, detentado por los franciscanos. En efecto, éstos consiguieron imprimir a finales de siglo dos ediciones (Burgos, 1683 y Madrid, 1690) de la Conversión de Piritú, de indios cumanagotos, palenques y otros, de fray Matías Ruiz Blanco y el Theatro mexicano; descripción breve de los sucesos exemplares históricos, políticos y religiosos del Nuevo Mundo occidental de las Indias (México, 1698), de fray Agustín de Betancourt, además de otras obras menores del mismo autor. Tentativa tardía y llena de compromisos, porque temerosa de mover aguas que se sabían peligrosas, de volver a proponer en un contexto difícil las grandes temáticas de corte lascasiano, que habían encontrado su clásica expresión en las dos obras maestras de la historiografía indiana franciscana, la Historia de los indios de Motolinia y la Historia eclesíastica indiana de Mendieta, con su corte apocalíptico de vindicación de la bondad de los indios, del bíblico Cortés y de la "Nueva Babilonia" de los espanoles laicos. Pero estas obras de Ruiz Blanco y Betancourt, a pesar de su escasa altura intelectual, son sin embargo interesantes como testimonio de una versión particular de la historia de Indias, oue todavía consigue abrirse paso en una situación hostil, como testimonio de la voluntad de la orden franciscana de contrarrestar, también en el plano de la "propaganda" historiográfica, la fuerza política poderosa de la Compañía de Jesús, y como obras, en fin, de transición, mediadoras, en la línea de compromiso inaugurada por la Monarquía indiana de Torquemada, de los excesos de los lascasianos y del pragmatismo de la razón de estado de los antilascasianos. Es una línea oue se verá reaparecer significativamente, por ejemplo, en la vindicación feijoniana de Hernán Cortés, donde el benedictino de Oviedo se equilibra en forma inestable entre el héroe mundano de un López de Gómara, y el humano y comprensivo cristiano, preocupado por el rescate espiritual y material de los indios de un Mendieta ${ }^{18}$. Se inicia así una competencia entre las dos órdenes, franciscana y jesuita, también en relación con la reciente prosecución de las conquistas de los territorios californianos, donde, después de varios enfrentamientos, los jesuitas guiarán la "evangelización" de la Vieja Califormia, mientras İos franciscanos se quedarán con la Nueva ${ }^{19}$.

17 Ibid, pp. 94-96.

18 lbid., pp. 102-104.

$19 \mathrm{Cf}$. Constantino Bayle, Historia de los descubrimientos y colonización de los padres de la Compañia de Jesús en la Baja California, Madrid, 1933. 
El jesuita trentino Eusebio Francisco Kühn, que había hecho una gran labor no sólo de evangelización sino científica ${ }^{20}$, consignó el resultado de ésta en una vasta obra, Favores celestiales de Jesús y de María Santissima del gloriosissimo Apóstol de la Indias (...). La Compañía, con gran tempestividad y buen olfato político, creyó oportuno que Kühn, en pleno desarrollo de la Guerra de Sucesión, dedicase su obra al nuevo monarca Felipe V. Sin embargo, de este autor sólo se publicó un mapa en 1705, en el que el jesuita demostraba la peninsularidad de California, mientras que los Favores celestiales quedaron inéditos ${ }^{21}$. En la caótica situación en que se encontraba España, precipitada en una verdadera guerra civil, probablemente la Compañía prefirió no ejercer sus poderes, cuyo destino además no estaba todavía bien dibujado en los nuevos planes políticos de los Borbones. La obra de Kühn se utilizó sólo más tarde, y su aportación fue aprovechada, como una fuente más, por el jesuita Andrés Marcos Burriel, del que hablaremos más adelante.

Los jesuitas intentaron también hacer frente al "monopolio" franciscano de la historiografía religiosa sobre la Nueva España. En 1694 el padre Francisco de Florencia publicó el primer tomo de una Historia de la provincia de la Compañía de Jesús de Nueva España. Pero la obra evidentemente no resultó satisfactoria, así que, a pesar de una edición que se hizo de su Menologio de los varones más señalados en perfección religiosa de la provincia de la Compañía de Jesús de Nueva España, publicada con revisiones y añadidos de Juan Antonio de Oviedo en 1747 (sin lugar ni imprenta), la Compañía prefirió dar el encargo de redactar una nueva historia de la Nueva España al padre Francisco Javier Alegre. Pero cuando la obra estaba por publicarse, la Compañía comenzó a perder poder, así que la Historia de Alegre pertenece a la historia de los jesuitas americanistas expulsados ${ }^{22}$.

La versión jesuita de la conquista de México evidentemente interesaba poco - y los padres tuvieron que darse cuenta-, lo que explica también la lentitud de la operación editorial. Ellos, además, sabían muy bien que la cultura europea, fascinada por la problemática del Nuevo Mundo en aquel momento crucial de su "crisis de conciencia", prefería soñar y reinventarse a sí misma con la poética y casi lírica revocación de Antonio de Solís y Rivadeneyra. Así que en 1691 ellos favorecieron la publicación en su Histoire de la conquête du Mexique ou la Nouvelle Espagne; mientras que en 1700 se publicaba en Amsterdam una traducción al francés de la vieja obra de Agustín de Zarate, Histoire de la décou-

20 Alfonso Trueba, El padre Kino, misionero itinerante y ecuestre, México, 1955.

21 Los Favores se publicaron tardiamente en nuestro siglo. Cf. Las misiones de Sonora y Arizona, comprendiendo la crónica titulada "Favores celestiales" y la relación diaria de la entrada al Noroeste por el padre E. F. Kühn. Versión paleográfica e índices por F. Fernández del Castillo, con noticias biográficas del P. Kino y sus exploraciones y fundaciones por E. Böse, México, 1913-1922.

22 Cf. Miguel Batllori, La cultura hispano-italiana de los jesuitas expulsados, Madrid, 1966, pp. $44-47$. 
verte et de la conquête du Pérou ${ }^{23}$ sobre la otra controvertida gran figura de la conquista, Gonzalo Pizarro. Además, a una Europa que, como escribe Hazard, "al contemplar la carta del Nuevo Mundo, volvía a poner en cuestión y a examinar los principios que dirigían al antiguo" 24 , la Compañía empezó entonces a proporcionarle, desde 1702, la larga serie de sus fascinantes Lettres édifiantes et curieuses ${ }^{25}$.

Pero en España otros eran los problemas con los que la cultura y el poder tenían que enfrentarse, para que la Compañía tuviera interés en insertarse de manera decisiva en la producción historiográfica sobre el Nuevo Mundo ${ }^{26}$ y en abrir la polémica, que tanto apasionaba a Europa, sobre el experimento que los jesuítas estaban llevando a cabo en Paraguay. Y esto porque en España el problema de las reducciones era un terreno bastante resbaladizo para la Compañía. Y no era una carta que valiera la pena jugar en el proyecto general de monopolizar la reestructuración cultural de la nueva dinastía. Reestructuración que tenía su centro en el control de la nueva Universidad de Cervera, que llevó adelante con gran habilidad el padre Finestre, del Colegio Imperial de Madrid y de los varios Colegios Mayores. Consiguientemente el interesantísimo aunque controvertido experimento de las reducciones del "estado" de los guaraníes se insertaba, a pesar de su misma peculiaridad, en el marco general de la conquista. Los jesuitas llevaban adelante con suma diligencia el papel de sujetar pacíficamente a los indios del Paraguay oriental y defender sus fronteras ${ }^{27}$; sin embargo, era un experimento que, por su misma delicadeza política, no exigía la circulación de una historiografía propagandista sobre el argumento.

La historia de la conquista y organización política del Paraguay ciertamente ya había tenido sus insignes representantes en la Orden, como Antonio Ruiz de Montoya, Juan Pastor, Diego Boroa; y a finales del siglo XVI había producido una interesante obra, aunque de corte limitado, dado que más bien se presentaba como una "inocua" crónica de acontecimientos externos que como una comprensión interior del significado general del experimento de las reducciones. Se trata de la $\mathrm{His}_{\text {- }}$ toria Provinciae Paraguariae Societatis Jesu de Nicolás del Techo. La Com-

23 Una segunda edición se publicó en 1706. Las obras de Solís y Rivadeneyra y las de Zárate figuran en las bibliotecas de De Brosses, Voltaire, D’Holbach. Cf. MI CHÈLE Duchet, Anthropologie et histoire au siècle des lumières, Paris, 1971. Cito por la trad. ital., Bari, 1976-1977, t. 4, p. 186.

24 Paul Hazard, La crise de conscience européenne, Paris, 1933. Cito por la trad. ital., Milano, 1968, t. 1, p. 24.

25 Las Lettres édifiantes fueron publicadas en español. Traducidas por Diego Davin en $1753-1757$.

26 Cf. también la Historia de la provincia de la Compañia de Jesús del nuevo Reino de Granada en la América, publicada en Madrid, 1741, del jesuita madrileño JosÉ CASSANI, profesor de matemáticas en el Colegio Imperial y el Orinoco ilustrado, del jesuita valenciano José Gumilla, publicado en Madrid en el mismo año.

27 Cf. Alberto Armani, "Città di Dio" e "Città del Sole". Lo "Stato" gesuita del Guarani (1606-1768), Roma, 1977, p. 233. 
pañía -el hecho no carece de significado- decidió no publicar la obra en España, sino en Lieja, y en latín además, en 1673. Y en 1704 se tradujo al inglés y se publicó en Londres, con el título de The history of the provinces of Paraguay, Tucuman, Rio de la Plata, Parana, Guaira and Urvaica. And something of the kingdom of Chili in South America. La traducción inglesa tuvo un cierto éxito, tanto que en 1732 se imprimió una segunda edición ${ }^{28}$. La Compañía se verá obligada, sin embargo, a sacar a la luz en España la temática paraguaya, pero sólo cuando el problema se haga acuciante: primero con la sublevación de los "comuneros" de Asunción y después con los conflictos derivados del Tratado de Límites.

Mientras tanto la presencia en el trono de España de un rey francés, y el nuevo clima de reformas que se empezaba a respirar suavizaron las polémicas sobre la "leyenda negra". Pero la muerte de María Luisa en 1714, el nuevo casamiento del rey con la ambiciosa e ignorante Isabel Farnesio, y la consiguiente expulsión del grupo de reformadores que gravitaban alrededor de la Princesa de los Ursinos, el alejamiento de Macanaz y la llegada a Madrid del cardenal Alberoni, determinaron un viraje hacia atrás de la política reformadora de Felipe V. El bloque político formado por los hombres de mediana nobleza del Consejo de Castilla, los llamados colegiales, y por los jesuitas, volvió a tomar en sus manos la supuesta defensa de la hispanidad contra el afrancesamiento del Estado, dando rienda suelta a la última violenta persecución inquisitorial contra los cripto-judíos. Mientras tanto, la política mediterránea de Alberoni relegaba a un segundo plano la problemática americana. Y en este clima de "restauración", la visión negativa de la conquista y de la evangelización española del Nuevo Mundo encontró un óptimo propagandista - en el plano de una historiografía muy ideologizada - en el español emigrado Francisco Coreal, que publicó en 1722 dos ediciones, una en Amsterdam y otra en París, de su Voyages aux Indes occidentales: verdadera mina para las "máquinas de guerra" que pondrán en marcha dentro de unos pocos años intelectuales como Prévost y De Pauw.

En España se tiene la impresión que el poder político y el poder religioso-cultural prefieren poner el asunto entre paréntesis. El cronista mayor, que era todavía el viejo Luis de Salazar y Castro, callaba sumergido en los papeles de su archivo, y nadie parecía interesado en solicitarlo para que publicase algo. La única nueva voz viene significativamente desde una colonia todavía "pobre" de la Corona, Venezuela, pero que pronto despertará el interés de los comerciantes vascos, que en 1728 crearán la famosa Real Compañía Guipuzcoana de Caracas, cuyos navíos tomarán el nombre de "navíos de la Ilustración" 29 . En esta época surge la voz del limeño de nacimiento, pero venezolano de

28 La traducción castellana apareció, con varios errores, en 1897.

29 Cf. RAMón de BASTERra, Una empresa del siglo xviii. Los navios de la Ilustración, Real Compañia Guipuzcoana de Caracas y su influencia en los destinos de América, Caracas, 1925. 
adopción, José de Oviedo y Baños, representante de aquella nueva aristocracia local cuyo poder tenía su origen en la explotación agrícola y pecuaria, y que protagoniza el desarrollo económico de la América dieciochesca. Oviedo y Baños, quien representaba a aquellos criollos elogiados por Feijoo en 1730, era un excelente hombre de negocios (controlaba una vasta producción de maíz, cacao y cría de ganado) y hábil político (alcalde, regidor perpetuo, capitán y teniente general). Escribió una Historia de la conquista y población de la provincia de Venezuela, que es obra de "grande y original historiador" 30 , y cuya primera parte se publicó en Madrid en 1723, mientras que de una hipotética segunda parte nada se sabe. Feijoo se expresa de él en tono elogioso ${ }^{31}$, pero su obra no parece haber tenido mucho eco. El orgullo criollo había intentado encontrar su cantor y su conciencia poética en el largo poema de un millar de octavas, Lima fundada o conquista del Perú (Lima, 1732), obra del catedrático de matemáticas de Lima, Pedro Peralta Barnuevo Benavides. Pero a pesar de que Sarmiento, en su Demonstración crítico-apologética del "Teatro crítico", "vindicase" con fuerza la obra de Peralta, y el hecho no carecía de significado ${ }^{32}$, ésta tampoco encontró eco alguno en la Península.

Sin embargo, algo parecía suceder con las publicaciones sobre temas americanos. En 1726 apareció la Relación historial sobre la catequesis de los indios Chiquitos del Paraguay del jesuita Juan Patricio Fernández, mientras que en 1729 se publicó en Madrid una nueva edición (la primera es de 1607) del Origen de los indios del Nuevo Mundo del dominico valenciano fray Gregorio García. Son éstos los años en los que Feijoo, en el tomo 2 de su Teatro crítico (1728), en el nuevo clima político y cultural de la tercera y cuarta fase del reformismo borbónico, se enfrenta con el problema del "error común" de que los "españoles americanos" "no tanto se gobiernan por razón, cuanto por instinto: como si alguna Circe, peregrinando por aquellos vastos países, hubiese transformado todos los hombres en bestias". Al contrario "sobran testimonios de que su capacidad en nada es inferior a la nuestra" 33 . Son los años del ministerio ilustrado de Patiño, y del retorno al interés por aquella América, que - supuestamente en decadencia - había enviado en 1727, con sorpresa general, quince millones de pesos en plata y oro, que podrían haber llenado las cajas del Estado vaciadas por los fabulosos "subsidios" que el nuevo confesor real, el jesuita irlandés Padre Clarke, había conseguido que fuesen enviados a Viena ${ }^{34}$. Son los años, en fin, en los que la política cultural de Felipe $\mathrm{V}$ empieza a desplazarse aceleradamente

30 Cf. Esteve Barba, op. cit., p. 320; Guillermo Morón, José de Oviedo y Baños, Caracas, 1958.

31 Véase Benito J. Feijoo, Teatro crítico, discurso VI, nota 10.

32 Ibid, nota 10 y MARTín SARMIENTO, Demostración crítico-apologética del teatro critico universal, Madrid, 1757, t. 2, nota 725.

33 Fejoo, op. cit., t. 2, discurso XV, nota 20.

34 Cf. Antonio Rodríguez Villa, Patiño y Campillo, Madrid, 1882, pp. 63-65. 
desde los clásicos centros de enseñanza de las universidades y de las escuelas a la "sociedad civil" y a sus instituciones.

Esta sustitución, cuyo guía y operador cultural es Feijoo, significaba también el comienzo del desplazamiento político-cultural de la Compañía de Jesús, el comienzo de una relación entre poder, cultura y sociedad sin la clásica mediación de una organización religiosa ${ }^{35}$, sino mediante intelectuales que, expresión de las nuevas exigencias y "curiosidades" de la sociedad civil, intentan dirigir de una nueva manera la formación de la "conciencia colectiva".

Esta nueva sociedad civil y esta reciente "burguesía" en expansión que en América representaban los criollos había tenido ya su primer enfrentamiento con la Compañía, en la llamada sublevación de los comuneros de Asunción. Apoyados por el juez José de Antequera Enríquez y Castro, los criollos paraguayos intentaron realizar el proyecto de destruir las reducciones de los jesuitas y de utilizar la mano de obra guaraní en sus encomiendas. Después de la terrible derrota de Tebicuary, los padres, con hábiles maniobras de guerrilla, frenaron la ofensiva de los comuneros y la conquista de Asunción en abril de 1727. El gobernador de Buenos Aires, Bruno de Zavala, pareció poner fin a la rebelión, pero la impolítica condena a muerte de Antequera en 1731, símbolo de los deseos de autonomía contra la ineficiencia de la burocracia virreinal, desencadenó nuevamente la insurrección que duró hasta $1735^{36}$.

La Compañía, que al defender sus reducciones protegía también la legitimidad virreinal, salió fortalecida de la guerra contra los comuneros y, a pesar del importante papel que había desarrollado y seguía fomentado en la política interior del país, su "servicio" a la monarquía en Paraguay no suscitó grandes entusiasmos. Hay que pensar que son éstos los mismos años de la ruptura entre la Corona y la Santa Sede, a causa de la ocupación de Parma y Nápoles, años en los que se reanuda la polémica regalista, guiada esta vez por el mismo Patiño, y que se concluyó con el Concordato de 1737. Y son éstos también los años del inicio de aquella nueva política americana, en que se establecen varias compañías comerciales, interesadas en que la reestructuración económica del Nuevo Mundo no fuese molestada por el ejemplo de organización, llamémosla así, "anticapitalista" y "antiburguesa" de las reducciones. Además, la reanudación del conflicto con Inglaterra, a causa de la competencia británica en el comercio americano, llevará a José

35 La Orden benedictina, a la que Feijoo pertenece, es, como bien se sabe, algo muy distinto a la Compañía, y si es verdad que detrás de Feijoo está su Orden, ésta deja a sus frailes, por tradición, una libertad de movimiento más amplia; además en el caso específico, ni la Orden benedictina es un "poder en el poder" como la Compañía, ni el adjetivo "benedictino" indica que Feijoo representa una mediación institucional entre sociedad y poder, sino todo lo contrario.

36 Cf. José Manuel Estrada, Ensayo histórico sobre la Revolución de los comuneros de Paraguay, Buenos Aires, 1865. 
Campillo a utilizar con la firma del nuevo Pacto de Familia (1743) la ayuda francesa en función de sus nuevos planes de política atlántica ${ }^{37}$. Por lo tanto, sólo porque el papel desempeñado por la Compañía en la guerra de Asunción había servido como elemento de freno a una situación peligrosa en aquel momento, Felipe V promulgó en 1743 la famosa Cédula Grande, que confirmaba todas las concesiones hechas por la monarquía en la administración autónoma de los guaraníes. Sin embargo, la historiografía jesuita anduvo muy cauta sobre este asunto.

En efecto, no fue publicada la excelente, aunque parcial, Historia de las revoluciones de la provincia del Paraguay de un diligente y atento historiador, el padre Pedro Lozano, en la que la narración de los acontecimientos llegaba hasta $1735^{38}$. Sólo se dio a la prensa en Córdoba, en 1733, su Descripción chorográfica del terreno, rios, árboles y animales de las dilatadissimas provincias del Gran Chaco, Gualamba, y de los ritos y costumbres de las innumerables naciones bárbaras e infieles que le habitan, con una cabal relación histórica de lo que en ellas han obrado para conquistarlas algunos governadores y ministros reales, $y$ los missioneros jesuitas para reducirlas a la fe del verdadero Dios. Obra seguramente de gran interés, con una visión muy moderna de histoire à part entière, pero de poco peso en la batalla defensiva a la que la Compañía estaba empezando a enfrentarse. En efecto, la otra obra de Lozano, la Historia de la Compañia de Jesús en la provincia del Paraguay (redactada entre 1730 y 1745), no fue publicada hasta los años 1754-1755 en Madrid, en la tipografía de la viuda de Martín Fernández. Y la Compañía dio el permiso de publicación sólo de la segunda parte, en la que Lozano proseguía la historia eclesiástica de Del Techo, es decir de la parte con más valor político, mientras que la primera, que era culturalmente la más interesante y en la que el historiador jesuita suministraba datos de histoire de la civilisation, permaneció inédita hasta $1873^{39}$.

Las razones de la "política historiográfica" de la Compañía en España hay que buscarlas en dos hechos. El primero es que el tema del Paraguay ya había tenido su intérprete y defensor de altura internacional en un historiador muy respetado en los ambientes innovadores europeos y españoles, Ludovico Antonio Muratori ${ }^{40}$. Me refiero al conocidísimo Il cristianesimo felice nelle missioni de’ padri della Compagnia di Gesú

37 Cf. el inédito Nuevo sisthema de govierno económico para la América: con los males y daños que le causa el que oy tiene de lo que participa copiosamente España; y remedios universales para que la Primera tenga considerables ventajas, y la Segunda mayores intereses. Año 1743, B.N.M., ms. 10949 y B.N.P., ms. 399-400.

38 Se publicó completa sólo en 1905. Cf. Guillermo Furlong Cárdiff, El padre Pedro Lozano, S.J., su personalidad y su obra. Bibliografía, Montevideo, 1930.

39 Cf. Esteve BarBA, op. cit., p. 581, que dice "no alcanzar la causa" de esta separación. Mucho éxito tuvo su descripción del terremoto de Lima de 1746, recogida en una Carta... escrita al padre Bruno Morales, de la que se hicieron varias ediciones (Lima, 1746; México, 1747; Córdoba, 1747) y se tradujo al inglés (London, 1748), al portugués (Lisboa, 1748) y al flamenco (s.1., 1749).

40 Cf. A. Mestre, "Muratori y la cultura española", en Atti del convegno internazionale di studi muratoriani, 1975 , t. 3, pp. 173-220. 
nel Paraguay, cuya primera parte se publicó en 1743 y la segunda en 1749. En este libro, cuyo autor no es jesuita, pero sí educado en los colegios de la Compañía, los padres encontraron un prestigioso baluarte contra la campaña antijesuita que se estaba desencadenando; por un lado las reducciones se presentaban como ejemplo de un gobierno fundado sobre "'una especie de 'delegado' en el ejercicio de la racionalidad', y por el otro el racionalismo de Muratori, que permitió la difusión de la obra en los ambientes ilustrados, era un racionalismo muy moderado y en el fondo lejano al racionalismo ilustrado porque "la razón muratoriana tiene la limitada función de redescubrir y asegurar un nudo de verdad que existía antes de la razón, y que, por lo tanto, no está de ninguna manera construido por ella" 41 .

El segundo hecho es que sobre la Compañía se estaba desencadenando otra borrasca, preludio de la tormenta final de la expulsión de 1767. Se trata de la aplicación del Tratado de Límites de 1750, que intentaba resolver la vieja cuestión de la colonia portuguesa de Sacramento. Ésta se tenía que devolver a los españoles, pues ellos cedieron a los portugueses la región paraguaya al este de los ríos Uruguay e Ibicuy. En esta región se encontraba una parte importante de las reducciones jesuitas, cuyo valor patrimonial los padres valoraban en millones de pesos. A pesar de que Fernando VI concedió una indemnización de veintiocho mil pesos a la Compañía, y que ésta envió un comisario, el padre Lope Luis Altamirano, con la orden de hacer cumplir las cláusulas del tratado, cuatro pueblos guaraníes se rebelaron en 1752 y pusieron en grave aprieto a los ejércitos luso-españoles. Las normas no muy claras impartidas por Altamirano a los padres, y el apoyo prestado por algunos jesuitas a los guaraníes insurrectos, indujeron al comisario español Gaspar de Munive, marqués de Valdelirios, a acusarlos de rebeldes a la Corona y de connivencia con los guaraníes ${ }^{42}$. Dada la delicadeza de la situación en la que la Compañía se vio envuelta y la dificultad de organizar rápidamente una defensa de su comportamiento, no le quedó a ésta más remedio que bloquear la publicación del Informe sobre los hechos enviado al marqués de Valdelirios por Manuel Antonio Flores $^{43}$, del Diario del capitán don Francisco Graell en la expedición contra los siete pueblos rebeldes de la banda oriental del Uruguay ${ }^{44}$ y de la Relación de lo ocurrido en la expedición que las armas de España y Portugal hicieron al territorio

41 Cf. N. BADALONI, "La ragione signorile di fronte all'immaginazione nella prima metà del Settecento”, en Storia d'Italia, t. 3, Dal primo Settecento all'Unità, Torino, 1973 , pp. 782-790. No creo que exista una traducción al castellano de la obra de Muratori.

42 Cf. sobre todo esto la obra, no siempre muy objetiva pero todavía muy útil, de W. Kratz, S.J., El tratado hispano-portugués de límites de 1750 y sus consecuencias, Roma, 1954 .

$43 \mathrm{Cf}$. Colección histórica completa de los tratados, convenciones, capitulaciones, cuestiones de límites y otros actos diplomáticos y políticos, París, 1862, t. 2, pp. 302-335.

44 Escrito en 1755-1756, está publicado en la Colección de documentos inéditos para la historia de España, Madrid, 1892-1896, t. 104, pp. 449-481. 
de las misiones de los jesuitas en el Paraguay para el cumplimiento del Tratado de Limites entre las dos Coronas, de Miguel de Silva Nades ${ }^{45}$. También se quedó momentáneamente inédito el diario de Tadeo Javier Henis, Persecución guaránica o diario de la guerra guaránica desde enero de 1754 al 13 de mayo de $1756^{46}$, que utilizó después Bernardo Ibáñez Echevarri en su violento panfleto antijesuita, El reino jesuítico del Paraguay, en plena polémica antijesuítica desencadenada después de la expulsión de la Compañía en $1767^{47}$.

Olvidada en los archivos se quedó también la Historia de las misiones de los llanos de Casanare y los ríos Orinoco y Meta ${ }^{48}$ del padre Juan Rivero, mientras que no consiguieron oponerse a la publicación del Informe, lleno de gravísimas acusaciones contra la Compañía, del general Matías de Anglís y Cotari ${ }^{49}$. Los padres, en una situación que se hacía cada día más difícil y que habían sentido, a causa justamente de algunos equívocos sobre la aplicación del Tratado de Límites, la salida de la escena política de un estimador de la Compañía, el marqués de la Ensenada, prefirieron silenciar lo más posible el caso. Ellos volverán a hablar ampliamente del asunto paraguayo sólo después de su expulsión, y las obras de Cardiel, Peramás, Sánchez Labrador y Muriel constituirán una parte importante de la contraofensiva de la Compañía después del decreto.

Una defensa de la actuación de los jesuitas en América vino de parte de dos grandes representantes del espíritu reformador, Jorge Juan y Antonio de Ulloa, que por encargo del marqués de la Ensenada habían preparado un detalladísimo informe sobre la situación americana. Pero, dado el carácter confidencial de la obra, cuyo título es Discurso y reflexiones políticas sobre el estado presente de los reynos del Perú, su gobierno, régimen particular de aquellos havitadores y abusos que se han introducido en unos $y$ otros, dase individual noticia de las causales de su origen, y se proponen algunos medios para evitarlo, y dado que en ella se contenía también una acusación terrible de incapacidad, estupidez y barbarie contra los indios, de los funcionarios y propietarios españoles y criollos, no se concedió permiso de publicación. La circulación del informe de Juan y Ulloa tuvo que ser, sin embargo, bastante amplia, dado que se encontraron varias copias del manuscrito original, pero fue seguramente la ya citada caída de Ensenada la que bloqueó la publicación de una obra que, en

45 B.N.M., mss. 10683 y 11319.

46 B.N.M., ms. 19242

47 Cf. Esteve Barba, op. cit., p. 489. La obra de Echevarri fue publicada en el t. 4 de la Colección general de documentos tocantes a la persecución que los regulares de la Compañia suscitaron y siguieron tenazmente por medio de sus jueces, conservadores, y ganando algunos ministros seculares desde 1644 hasta 1660 contra D. Bernardino de Cárdenas... obispo del Paraguay, Madrid, 1768-1770

48 Cf. Esteve Barba, op. cit., pp. 337-338. En 1739 el ya citado Gumrlla había publicado en Madrid una Breve noticia de la apostólica y exemplar vida del angelical y venerable padre Juan Rivero, de la Compañía de Jesús.

49 Cf. Bentto Sánchez Alonso, Historia de la historiograjía española. Ensayo de un examen de conjunto, Madrid, 1950, t. 3, p. 155. 
la edición de Londres de 1828, cuidada por David Barry, contribuyó no poco a la divulgación de la "leyenda negra" en el siglo XIX ${ }^{50}$. Como se ve, la maraña entre política reformadora, Compañía de Jesús e historiografía indiana se estaba haciendo cada vez más intrincada y complicada.

Cansado de la incapacidad del cronista mayor Miguel Herrero Ezpeleta en el desempeño del cargo según las exigencias de la nueva situación creada por el equipo ministerial reformador, Felipe $\mathrm{V}$ había otorgado "de futura" a la Academia de la Historia el derecho de nombrar el cargo. A la muerte de Ezpeleta en 1750, Fernando VI, olvidando la designación "de futura", y previa cancelación del título otorgado a la Academia, nombró cronista mayor al gran organizador de la empresa feijoniana en Madrid, fray Martín Sarmiento ${ }^{51}$. Sarmiento no hizo nada ${ }^{52}$ y en 1755 la Academia de la Historia reinvindicó con justa razón su título, pero tampoco hizo nada; habrá que esperar al reinado de Carlos III para que algo suceda en el sector de la historiografía oficial sobre las Indias ${ }^{53}$.

Mientras tanto la historiografía americanista había empezado a encontrar entre los seglares hombres capaces de llevarla adelante en el espíritu indicado por Feijoo. Un ejemplo de una nueva manera de enfrentarse con el problema de la historia de América fue la Idea de una nueva historia general de la América septentrional, fundada sobre material copioso de figuras, sýmbolos, caracteres y geroglificos, cantares y manuscritos de autores indios, últimamente descubiertos: pequeño volumen en $4^{\circ}$ de unas 260 páginas, obra del caballero milanés Lorenzo Boturini Benaducci, publicado en Madrid en 1746. Durante su estancia en la Nueva España, Boturini había recogido un material inmenso e insólito, un verdadero "museo histórico indiano" que, a causa de una serie de desgracias, no pudo traer personalmente a España y tuvo que utilizar sólo de memoria. "Buscó - escribe de Boturini, Ballesteros- en los materiales que le servían como fuentes, no la mera estructuración de los hechos históricos, sino su filosofía, su razón de ser, su enlace con el curso general

50 Ibid., pp. 148-149

51 Cf. Esteve Barba, op. cit., p. 133.

52 Que yo sepa, no hay escritos suyos sobre asuntos americanos. Cf. MARCELino Gesta y Leceta, Indice de una colección manuscrita de obras del R.P. fray Martín Sarmiento, Madrid, 1888.

53 La Academia, en lugar de redactar aquella historia de América que la España de Carlos III exigía, encargó la traducción de The history of America, de W. Robertson (London, 1777 y 1794). La traducción, sin embargo, fue interrumpida por presión inquisitorial, y de la "contraofensiva informativa" sobre la historia de América fue encargado, por Carlos III, "un historiador marginal, Juan Bautista Muñoz, cosmógrafo mayor de Indias, filósofo ecléctico, valenciano y amigo de los círculos ilustrados de su tierra" (G. ZaraGoza y R. García CírCel, "La polémica sobre la conquista española de América. Algunos testimonios en el siglo xviII", en $H N S$, p. 374). Muñoz se hizo cargo también de publicar parte de la Historia de la conquista de la Nueva Galicia del bachiller Matías de la Mota Padilla, que no había conseguido publicar en 1742. 
de la historia." ${ }_{54}$. Boturini era hombre que conocía muy bien no sólo la cultura clásica, sino también la contemporánea, y sorprende, por ejemplo, su conocimiento profundo y su adhesión a las ideas de un autor entonces poco conocido, pero que revelará después haber sido una de las figuras más importantes de la primera mitad del XVIII, Giambattista Vico. La Idea de Boturini impresionó favorablemente, tanto que el marqués de la Ensenada, no pudiéndolo nombrar cronista de Indias, cargo que detentaba Ezpeleta y "de futura" la Academia de la Historia, lo nombró cronista en las Indias, que era nombramiento como otro y una artimaña para sustituir de facto al perezoso Ezpeleta. Boturini trazó en seguida un ambicioso proyecto de Historia general, que fue oficialmente aprobado. Pero las dificultades que encontró en su redacción, a pesar de la ayuda de Mayans y el apoyo de Carvajal ${ }^{55}$, y su muerte prematura en 1751, no le permitieron acabar la empresa. Nos queda sólo el primer tomo de Cronología indiana, redactado en 1749 , que, con algunas de las otras piezas de la colección de Boturini que llegaron finalmente de México, sólo pudieron ser utilizadas más tarde por Juan Bautista Muñoz en su Historia del Nuevo Mundo, que se publicaría en Madrid en $1793^{56}$.

El nuevo clima intelectual de renovado interés por la situación económica - la segunda edición de 1742 de la gran obra de Jerónimo de Uztáriz, Theórica y práctica de comercio y de marina, es la que tuvo verdadera circulación- motivó a José Gutiérrez de Rubalcava a enfrentarse con los problemas económicos de la historia americana. Profesor de derecho y asesor de marina en Cádiz, Gutiérrez le dedicó al marqués de la Ensenada su Tratado del comercio de las Indias occidentales. Compendio histórico del comercio de las Indias, desde su principio a su actual estado, publicado en 1750 . No se trata de una verdadera obra de historia económica, sino de una colección de datos, desde luego muy precisos, para una posible historia del comercio americano, pero que resultó ser muy útil como manual de derecho administrativo y comercial para los operadores económicos de las nuevas compañías de comercio colonial. Sobre asuntos administrativos y económicos trata también el Discurso sobre los males y abusos de la América y medios de remediarlos de Francisco Malhorti, escrito que, a pesar del espíritu reformador e ilustrado que lo anima, probablemente por contener acusaciones contra las clases dirigentes americanas, quedó inédito, como el anteriormente citado Informe de Juan y Ulloa ${ }^{57}$. Se publicó entre 1746 y 1748 otra obra, siempre de carácter administrativo, el Theatro americano del criollo Antonio de Villaseñor, contador general de Azogues: obra

54 Cf. Manuel Ballesteros Gaibrois, pról. a la obra de Boturini, en Documentos inéditos para la historia de España, Madrid, 1948, t. 6, pp. xi-lxvi.

55 Sobre la relación entre Boturini y Mayans, véase Antonio Mestre, Historia, fueros, y actitudes políticas. Mayans y la historiografía del siglo xviii, Valencia, 1970, pp. 313-328.

56 Cf. Esteve Barba, op. cit., pp. 265-267.

57 El Discurso se encuentra en B.N.M., ms. 11039 
de carácter oficial, no muy interesante, pero llena de datos concretos y útiles que necesitaba aquella burguesía virreinal a la que el Theatro de Villaseñor estaba dirigido.

En otra vertiente, no económica sino de recuperación de ciertas temáticas "cripto-lascasianas" — propuesta sutilmente por el mismo Feijoo, con un discurso de estructura oscilante entre valoración de la realidad del "buen salvaje", inutilidad de su colocación en el contexto de la absurda utopía de la "ciudad de Dios" y "vindicación" de los aspectos positivos de la conquista— ${ }^{58}$, se coloca la operación editorial de Andrés González de Barcia. Este personaje, que ocupó altos cargos políti$\cos$ en el reinado de Felipe $\mathrm{V}$, consideró importante hacer accesible a un público más amplio, al mismo público que devoraba con creciente curiosidad intelectual los Discursos y las Cartas de Feijoo, algunas de las obras más interesantes y fascinantes, a su parecer, relativas al gran problema del descubrimiento y de la conquista. En 1749 publicó, en tres volúmenes, su colección de Historiadores primitivos de las Indias occidentales, que es una especie de antología de los escritos de Colón, Cortés, Fernández de Oviedo, Herrera, Cabeza de Vaca, Gómara, Garcilaso el Inca, etc ${ }^{59}$. Las variadas temáticas sobre el Nuevo Mundo tenían así divulgación en el marco de los nuevos intereses por la política atlántica en que se encajaban los planes de reforma estatal, económica y cultural de Ensenada y Carvajal. Sólo que la propuesta de González de Barcia ponía en circulación una visión de la conquista que poco debía agradar a los nadres de la Compañía, porque contraponía a una historiografía "eclesiástica" una historiografía "seglar", en la que sutilmente emergían dos ideas "peligrosas". La primera era una visión del hombre natural en la que se filtraba un radicalismo evangélico, una reivindicación de la conciencia personal contra toda forma de autoritarismo y contra la concepción de que el hombre primitivo no posee sentimientos profundos, y tiene por lo tanto que ser controlado por el poder religioso, ideas que olían a jansenismo. La segunda era una concepción en la que se mezclaban, con un corte típicamente feijoniano,

58 Cf. B. J. Feijoo, Teatro crítico, t. 4, discurso X ("Fábula de las Batuecas y países imaginarios"). Véase también Teatro crítico, t. 5, discurso I, nota 10; t. 8, discurso VII, notas 34-41; y Cartas eruditas, t. 2, carta 26.

59 Bajo el seudónimo de Gabriel de Cárdenas y Cano, González de Barcia había publicado un Ensayo cronológico para la historia general de la Florida (Madrid, 1723) y una edición de La Florida del Inca (Madrid 1722-1723), de la Historia general del Perú (Madrid, 1722) y de los Comentarios reales de Garcilaso (Madrid, 1723); una edición de la Monarquía indiana y de los Veinte y un libros de rituales de Juan de Torquemada (Madrid, 1723); una edición "corregida y aumentada de notas" de las Décadas de Herrera (Madrid, 1725-1730 y varias portadas). Mientras que en 1737-1738 publicó, con varias adiciones, la obra de ANTONio de León Pinelo, Epitome de la biblioteca oriental y occidental, naútica y geográfica: tres gruesos volúmenes en folio con texto a dos columnas, verdadero "cimiento de la bibliografía americanista". Como se puede ver, en las elecciones editoriales de González de Barcia se juntan criticismo historiográfico, a la Mayans, por un lado, y reevaluación de ciertas temáticas americanas, hecha por Feijoo, por el otro. 
criticismo historiográfico (González de Barcia había preparado un estudio sobre Nicolás Antonio) ${ }^{60}$ y reforma del concepto tradicional de relación entre política y religión. Esta visión le daba un golpe indirecto a la Compañía, pues subrayaba el carácter más jurídico-político que éticoreligioso de su evangelización, y volvía a unir jansenismo y regalismo en un momento en que los padres tenían que defender, con la autonomía de su gestión religioso-administrativa de las reducciones, también la existencia en ellas de un patrimonio que se alejaba de un modo anómalo del control regio.

Pues bien, los jesuitas habían seguido siempre una política cultural muy clara en relación con el espinoso problema de la penetración en España de las corrientes jansenistas. La Compañía era profunda conocedora de los más sutiles canales secretos por los que la "herejía" jansenista había penetrado y se había desarrollado en España en la segunda mitad del xviII y del influjo que parecía volver a tener, a pesar de su derrota teológica, en la nueva situación determinada por el cambio de dinastía. Mestre ha demostrado muy bien que no se puede colocar la reanudación del jansenismo dieciochesco en España en la época de Carlos III, como hasta ahora han afirmado historiadores como Sarrailh y $\mathrm{Herr}^{61}$, sino que existe todo un período de gestación en la primera mitad del siglo. En esta época sobresale la figura de Mayans, quien reedita en 1727 la traducción de Interián de Ayala del Catecismo histórico de Fleury, y prologa en 1739 la traducción de las Costumbres de los israelitas y de los cristianos, además de ser admirador y difusor en secreto - cuando ocupaba el cargo de bibliotecario real- de las obras del jansenista Bernhard van Espen Zeger ${ }^{62}$, cuyos textos se publicaron sólo después de la expulsión de la Compañía.

La actitud de los jesuitas frente al jansenismo es, sin embargo, singular, porque si por un lado ellos impiden la circulación de aquellas ideas del Augustinus que eran contrarias a la estructura lessiana y molinista de su enseñanza y comportamiento religioso, por el otro hacen de la Inquisición, por ellos controlada, un instrumento de fundamental importancia en la lucha regalista que desemboca en el primer Concordato de 1737. En efecto, la conexión que encontramos en Francia entre gali-

60 A. Mestre, Historia, fueros..., ed. cit., p. 404.

61 A. MEstre, "Religión y cultura en el siglo XVIIr español", en Historia de la Iglesia en España. T. 4: La Iglesia en la España de los siglos xvii y xviii, Madrid, 1979, pp. 639-677. Cf. también JOËL SAUGNIEUX, Le jansénisme espagnol, ses composantes et ses sources au xviii siècle, Oviedo, 1975. Émile APPOLIS, en Entre jansénistes et zelanti, le "Tiers Parti"' catholique au xviiie siècle, Paris, 1960, al tratar en passant el jansenismo español, justamente, a mi parecer, lo había colocado en una zona intermedia, sin que por esto fuese aclarada debidamente la estructura y la dinámica interna de esta zona, que queda no sólo imprecisa sino ambigua. En su posterior trabajo, Les jansénistes espagnols, Bordeaux, 1966, coloca el fenómeno jansenista en la segunda mitad del XVII .

62 Cf. Antonio Mestre, Ilustración y reforma de la Iglesia. Pensamiento político religioso de don Gregorio Mayans y Siscar (1699-1781), Valencia, 1968, pp. 386-396. 
canismo parlamentario y jansenismo en España no se da en absoluto, tanto que entre regalismo y jansenismo hay que hacer siempre una neta distinción; si no, se incurre en contradicciones en las que los jesuitas "regalistas"' de facto ${ }^{63}$, pero ferozmente antijansenistas, caen por su antijansenismo bajo la acusación de antirregalistas, y esta acusación se transformaría en una de las motivaciones de la expulsión. Tras estas disputas teológico-jurisdiccionales se escondían sólo intereses políticos y luchas de grupos por el control del poder, además de ideas distintas, obviamente, de cómo llevar adelante, y con el apoyo de qué sectores de la "sociedad civil", el camino del reformismo ilustrado.

A la Compañía la utilizaron los varios equipos ministeriales reformadores, porque era ella la que tenía el control de los colegios mayores y también los sectores mayoritarios de las universidades, y porque bien conocida era su elasticidad de adaptación a la voluntad del poder político, y la inteligencia de sus miembros. Sus vínculos estrechos con la alta nobleza se emplearon para controlar desde el interior su potencial destructor, con la ilusión quizás de promover las reformas sin recurrir a un "desgarro" excesivamente traumático con la así llamada "sociedad cerrada". Pero cuando terminó la "aventura" internacional de Alberoni, los problemas de cómo llevar adelante las reformas se replantearon de manera urgente, y la cuestión de la estructuración de la política cultural se presentó en términos de la necesidad de conquistar capas sociales más amplias para el proyecto reformador. Además, la tensión intelectual, controlada y favorecida por la Compañía, que había permitido transformar en mayoritario el grupo de los "nuevos nobles", se vino abajo. En otras palabras, cuando el problema se planteó como necesidad de conectar el reformismo borbónico con el específico nivel de conciencia del "habitante de la sociedad civil", la función de los padres de la Compañía empezó a entrar progresivamente en crisis. Es una crisis que tiene un camino zigzagueante y "secreto" que se vislumbra en seguida, ya que es a Feijoo, representante de la Orden benedectina, a quien se le confía progresivamente la ejecución de toda la maniobra de política cultural del equipo ministerial reformador, y cuya sanción ofi-

63 No es aquí el lugar para reabrir el problema de las acusaciones de "antirregalismo", "antijansenismo", "antirreformismo" de los padres, que se transformarán, a pesar de todas las investigaciones minuciosas sobre el problema, en el juicio, que se vuelve a repetir, de que la expulsión de los jesuitas constituyó el triunfo de la ideología regalista. Regalismo es una palabra con varios matices. Baste sólo con pensar lo que fue el resultado más importante del "regalismo práctico" del reinado de Fernando VI, el Concordato de 1753. ¿Quiénes fueron los protagonistas de toda la operación? El jesuita confesor real padre Rávago y el marqués de la Ensenada, amigo de los padres; y entre los "intelectuales", encargados de dar justificación histórico-jurídica al acuerdo, encontramos al "jansenizante" Mayans y al jesuita Andrés Burriel. Lo que es cierto es que el Concordato de 1753 abrió el paso al regalismo jansenizante, que dominó la escena política del reinado de Carlos III, y representó al mismo tiempo una "victoria" de la Compañía y el comienzo de su segregación. Pero ésta es ya otra historia, que no viene al caso examinar aquí. 
cial es el famoso "no debe haber quién se atreva a impugnarlos" (los escritos de Feijoo), contenido en la real orden de Fernando VI de junio de 1750. La maniobra tenía la finalidad de recuperar, sin ruptura, las varias islas del abigarrado archipiélago de la sociedad española — sólo potencialmente aliada para el nuevo proyecto de reforma- para la nueva cultura de las Luces.

La Compañía, que había pensado siempre en términos de control y organización de la cultura dentro del ámbito restringido de las escuelas, tuvo que pasar a la defensiva. Es en este contexto más amplio donde hay que colocar el caso de la prohibición de las obras del cardenal italiano Noris, impuesta por el Inquisidor general Pérez Prado, longa manus de la Compañía, y apoyada por el confesor de Fernando VI, el jesuita padre Rávago, con el pretexto de que se trataba de obras jansenistas. Roma, que había ya decretado explícitamente la ortodoxia del agustino Noris, no pudo tolerar este acto de independencia de la Inquisición española. El escándalo se hizo público y "se convirtió en un asunto de Estado", en el que — como subraya muy bien Mestre- "el monarca -o si se prefiere, su confesor- utiliza el regalismo para atacar las doctrinas que considera jansenistas" 64 . El "asunto Noris" pudo ser resuelto sólo con la exoneración de Rávago del confesionario real. Una derrota para la Compañía y una demostración más de que las ambigüedades de Ensenada, oscilante entre su manipulación por un lado y su segregación de hecho por el otro, debían superarse. La situación se complicó aún más porque al "caso Noris" se sobrepuso a la cuestión del Tratado de Límites, del que ya hemos hablado.

En este contexto cada vez más intrincado que viene a determinarse en la segunda etapa del reinado de Fernando VI, que sigue a la caída de Ensenada, es donde hay que colocar la publicación, en 1757, de los tres volúmenes de las Noticias de la California, de su conquista temporal y espiritual hasta el tiempo presente. Sacada de la historia manuscrita, formada en México año 1739 por el padre Manuel Venegas de la Compañía de Jesús, y otras noticias y relaciones antiguas y modernas. La obra se publicó anónima y bajo la forma de refundición de la de Venegas, pero detrás de ella estaba el jesuita Andrés Marcos Burriel, amigo del "jansenizante"' Mayans, mediador en la polémica que había enfrentado a éste con Flórez después de la publicación del segundo volumen de la España sagrada. También fue director de la comisión encargada en 1749, a raíz de las controversias regalistas, de investigar los archivos eclesiásticos españoles, y uno de los representantes más insignes de la historiografía crítica del XviII.

La obra de Burriel está construida sobre una elaboración de datos efectivamente proporcionados por el padre Venegas, pero también por Juan María de Salvatierra, Francisco María Piccolo, Juan de Ugarte, además de una serie de papeles del archivo virreinal de México y de las ya citadas Flores celestiales de Kühn. El significado político-cultural

64 A. Mestre, "Religión y cultura...", véase supra, nota 61. 
de esta obra, que se presenta aparentemente como una repetición más de varios tópicos sobre la "meritoria" labor de los jesuitas en la evangelización del Nuevo Mundo, está demostrado por el interés apasionado y casi fanático, al parecer inexplicable, de Burriel en la publicación de la obra; pues él tenía que atender al complicadísimo control y coordinación del equipo de investigadores que trabajaban bajo su dirección en los varios archivos de España, y por la batalla que tuvo que sostener para que los censores de la Academia de la Historia no le suprimiesen varios pasajes de la obra. Uno de los censores le había hecho notar que, para demostrar la justicia de la acción jesuita en el Nuevo Mundo, no era "necesario poner a los ojos del público y a la censura de toda Europa la injusticia de algunos nacionales, ni los defectos que se aprehenden en el Gobierno" 65.

Burriel era un experto historiador y estaba muy ligado también a las maniobras políticas de los intelectuales de la Corte. Construyó su obra con inteligencia y gran finura psicológica; en ella, la denuncia de los abusos y mala administración americanas se acompañaban de una serie de propuestas de reformas, pues intentaba hacer recuperar a la Compañía el papel directivo de la política cultural, que estaba pasando cada vez con mayor rapidez en manos de los "feijonianos". Téngase presente que una operación semejante estaba también llevándola a cabo el jesuita Francisco de Isla que pocos meses después, en 1758, publicaría su Fray Gerundio, contra el cual en seguida se levantó el grupo capitaneado por el joven conde de Peñaflorida, el de los famosos "caballeritos de Azcoita" representantes de la nueva generación, que protagonizaría la "primavera de las luces" de los años sesenta.

El hecho es que la misma estructura de poder se presenta en este momento más articulada, y la Compañía, antes instrumento precioso para un control "inteligente" de la censura inquisitorial por su capacidad de hacer operativas ciertas decisiones, ahora ya no es útil, pues su fuerza política puede resultar peligrosa ("un Estado dentro del Estado"), porque se corre el riesgo de que la Compañía impida la participación de la "sociedad civil" en la operación de reforma de las costumbres, y de inserción de España en el circuito del gran debate cultural europeo. Ya no conviene que las relaciones entre intelectuales y poder sean mediadas por la Compañía. Es preferible mantener un clero más inculto, aquél satirizado violentamente por Isla, pero más aquiescente al poder. Véase, por ejemplo, el apoyo al gobierno y contra los jesuitas, que darán las órdenes menores en el motín contra Esquilache. También la culta Orden benedictina, que había desarrollado muy bien su papel alternativo a la Compañía, había agotado su tarea. Para el grupo de los amigos del conde de Peñaflorida, el mismo Feijoo es ya sólo un punto de referencia cultural, completamente independiente de su pertenencia a una orden religiosa, simple constelación de ideas y de indicaciones metodológicas.

65 Apud, Sánchez Alonso, op. cit., p. 167. 
Así es que con la publicación de las Noticias de Burriel los cabos se atan, y lo que puede ser considerado el último fruto de la "historiografía indiana" del reinado de Fernando VI demuestra, una vez más, la estrecha relación existente entre política e historiografía, y cómo esta última no era ni podía ser una operación cultural que, para legitimarse, necesitara del simple despegue desde la plataforma secreta de la voluntad o curiosidad de cada autor, sino que se insertaba como una pie$z a$, a veces fundamental, del mapa de las astucias y de las instancias del poder. "Ya que V.R. - escribe Burriel en una carta al padre Rávago- no me dejó ir a las Californias, me las traje yo acá del modo posible". Sólo que acá él se había traído no solamente su "querida California", su sueño; hacia acá se traía una profundidad de la historia de su propia "patria", y él, expertísimo conocedor de los secretos pasillos de los archivos de esta historia, lo sabía muy bien. Pero ya había pasado el tiempo en que era posible la aristocrática búsqueda de la estratificación insondable sobre la que narcisísticamente pasea nuestro yo. Burriel había querido volver a proponer, cubierto por la capa de la seriedad del criticismo historiográfico, con una operación llena de ambigüedades y quizás poco clara para él mismo, el peligroso tema de "América como pueblo utópico", que Feijoo había violentamente destruido en el décimo discurso del tomo 4 de su Teatro crítico, y presentarlo en un momento en que la observación de Feijoo - "la gloria de los inventores es $\sin$ comparación mayor que la de los conquistadores" - ${ }^{66}$ se estaba transformando en conciencia política del grupo fundador del gran experimento reformista de las Sociedades de Amigos del País.

Giovanni Stiffoni

Universidad de Venecia. 